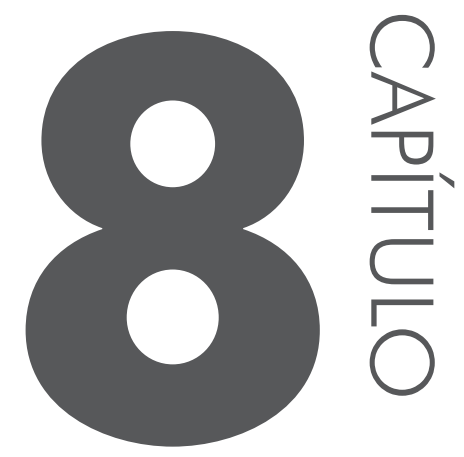

\title{
A Kilamba e o Quilombo: narrativa de viagem a Luanda
}

\section{Ilka Boaventura Leite, Cristine Gorski Severo e Marcos Fábio Freyre Montysuma \\ Univesidade Federal de Santa Catarina}

Nosso encontro com Angola se deu no ensejo da primeira missão científica do "Projeto Kadila: culturas e ambientes - diálogos Brasil-Angola", desenvolvido pelo NUER/UFSC com apoio do Programa Mobilidade Internacional da Capes/ MEC e da UFSC em 2013. Tal missão nos conduziu ao Instituto Superior de Educação, situado na área denominada Kilamba, nas proximidades do campus da Universidade Agostinho Neto. A palavra Kilamba origina-se do termo quimbundo "kilombo" que quer dizer "reunião, ajuntamento de pessoas para comerciar ou se organizar militarmente para a defesa de determinado território ou região". $\mathrm{Ou}$, ainda, como registrou o famoso historiador português Cadornega, radicado em Angola no século XVII, o "quilumbo" designava um juramento de fogo em local de iniciação ritual de jovens guerreiros. Kilamba, portanto, designa "alguém de coragem, chefe militar" e foi adotado como apelido de guerra por Agostinho Neto durante a Guerra de Libertação de Angola, em que se tornou o líder máximo, símbolo da nova nação. 


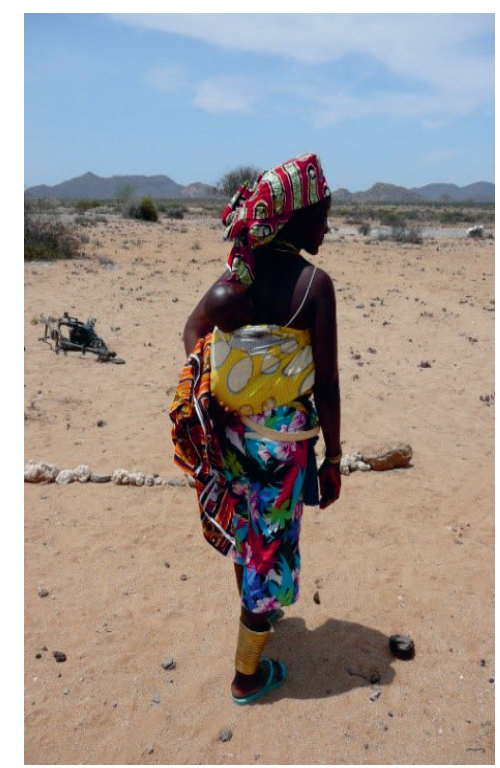

Figura 8.1 - Pastora no Kuroca. Fonte: Ilka B. Leite Acervo NUER .

A palavra Kilamba, no contexto pós-guerra de reconstrução de Angola, foi escolhida para nomear um imenso conjunto habitacional construído pelos chineses nos arredores de Luanda. Essa construção visa, entre outros, a amparar o crescimento vertiginoso e acelerado do projeto de formação educacional desenvolvido pela Universidade Agostinho Neto. Nos diálogos entre Brasil e Angola, ao percorrermos a Kilamba, encontramos com o quilombo, que no Brasil representa o grande projeto de conferir direitos territoriais aos africanos escravizados e seus descendentes na atualidade. O kilombo, portanto, no espaço próprio de cada lugar, quer dizer direito à terra e à cidadania, inclusão social e respeito aos direitos humanos.

Essa Kilamba que percorremos em nossa curta estadia não lembra em nada nossos conjuntos habitacionais, sobretudo pela qualidade dos edifícios e excelência de sua infra-estrutura. Trata-se de um pequeno exemplo da Angola atual, que se encontra em grandioso projeto de reconstrução de diversos setores, tais como redes viárias, sistemas habitacional, médico, econômico, político e cultural. A impressão que temos é que o país se transformou em um canteiro de obras, tomado como signo de uma mudança que sugere a velocidade com que os angolanos buscam superar e honrar com generosidade todas as vidas que foram levadas pelas guerras. Nesse contexto, o maior desafio para os angolanos hoje é reconstruir um sistema educacional que possibilite o fortalecimento de uma comunidade nacional sem a perda da riqueza cultural que advém dos diversos povos e culturas formadoras da nação. 
Muito nos surpreendeu, nessa nossa passagem, o contato direto com as sonoridades linguísticas das chamadas "línguas angolanas" de origem bantu, as quais incluem o kimbundo, o kikongo, o umbundo e o tchoque, para mencionar as mais faladas. Tais línguas funcionam paralelamente ou de forma amalgamada ao português, a única língua oficial de Angola. Nesse contexto angolano de multilinguismo, um dos desafios das políticas linguísticas do país tem sido a valorização das línguas nacionais em contextos formais e oficiais, uma vez que o valor econômico e político da língua portuguesa tem, aos poucos, amortecido o significado simbólico e cultural das demais línguas. Além disso, a paisagem linguística inclui também o russo, o chinês, o ídiche, o espanhol, o inglês e o francês. Essas línguas, em conjunto com seus falantes, muitas vezes bilingues ou multilingues, complexificam o cotidiano das comunicações, das trocas e dos processos de desenvolvimento educacional em curso no país.

No processo de preparação de nossa viagem à Angola, nos chamou atenção o depoimento de estudantes angolanos, que compartilham de nossa vida universitária, sobre sua experiência pluricultural e multilingue em Angola e, mais especificamente, em Luanda. De fato, o maior desafio para os angolanos parece ser a reconstrução de um país que possibilite o fortalecimento de uma comunidade nacional em paralelo com o respeito à riqueza cultural que advém dos diversos povos formadores da nação. No âmbito dos diálogos educacionais e acadêmicos, busca-se efetivamente contribuir para o fortalecimento dos estudos sobre a África, aproximando docentes e estudantes brasileiros e angolanos, com vistas a aprofundar o nosso interesse pela história da África e pelos estudos afro-brasileiros, aspectos consignados pela Lei 10.639/2003 (atual 11.645/08), que estabelece e incentiva o aprimoramento desses conteúdos na educação brasileira. O desconhecimento e quase ausência de conteúdos curriculares sobre a África e as culturas afro-brasileiras constitui um dos fatores que contribuem hoje para o enfraquecimento do atual sistema de ensino e para a disseminação, no Brasil, das intolerâncias e dos conflitos raciais.

O projeto Kadila, que nos conduziu à Angola, vincula-se ao NUER e surgiu como desdobramento do projeto Olhares de África, iniciado em 2007 em Moçambique. Em 2011, o NUER consolidou sua parceria com o CE.DO, Centro de Estudos do Deserto, associação civil de caráter científico, não governamental e sem fins lucrativos, localizada em Namibe, sudoeste de Angola, e coordenado pelo professpor Samuel Rodrigues Aço, vinculado ao departamento de Antropologia da Universidade Agostinho Neto. O CE.DO tem se debruçado sobre a construção de conhecimentos sobre o deserto do Namibe, localizado nas fronteiras entre o sudoeste de Angola e a Namíbia. Trata-se de uma região praticamente inexplorada pelas pesquisas acadêmicas recentes, sobretudo tendo em vista a posição dessa região no quadro de desenvolvimento da Angola contemporânea. A 
região está situada na área do Deserto de Kalahari, de clima semi-árido, em que o ecossistema condiciona drasticamente qualquer tipo de atividade econômica ou de produção, fato que motiva movimentações transumantes. É nesse contexto que o CE.DO desenvolve atualmente o "Observatório da transumância”, cujo objetivo é obter um retrato detalhado do fenômeno da transumância no sudoeste de Angola.

A ótica inter e multidisciplinar que caracteriza o diálogo aqui proposto entre Brasil e Angola, de forma geral, e entre pesquisadores da UFSC, da UAN e CE.DO, de forma específica, busca um entendimento sobre a multiplicidade de fluxos e modalidades da experiência migratória em termos regionais, religiosos, linguísticos, literários, artísticos, bem como sobre as modalidades variadas da vida produtiva e comunal. Trata-se, com isso, de construir novas narrativas para a compreensão de fenômenos que extrapolam categorias pré-formatadas ou coloniais e que afetam Angola e Brasil de diferentes modos e com especificidades próprias.

Desde a Conferência de Berlim, em 1888, Portugal assumiu o controle oficial sobre as pessoas, as línguas e o território de Angola, área constituida a partir de desdobramento do antigo reino do Kongo. Angola e seu povo têm laços históricos e culturais profundos e indissociáveis com o Brasil. O reconhecimento disso na formação da nossa brasilidade nos trará, por certo, maturidade para lidarmos tanto com a nossa própria diversidade cultural - por muitas vezes silenciada como com os inevitáveis diálogos interculturais. Terminamos reafirmando os dizeres generosos de nossos anfitriões: "somos irmãos".

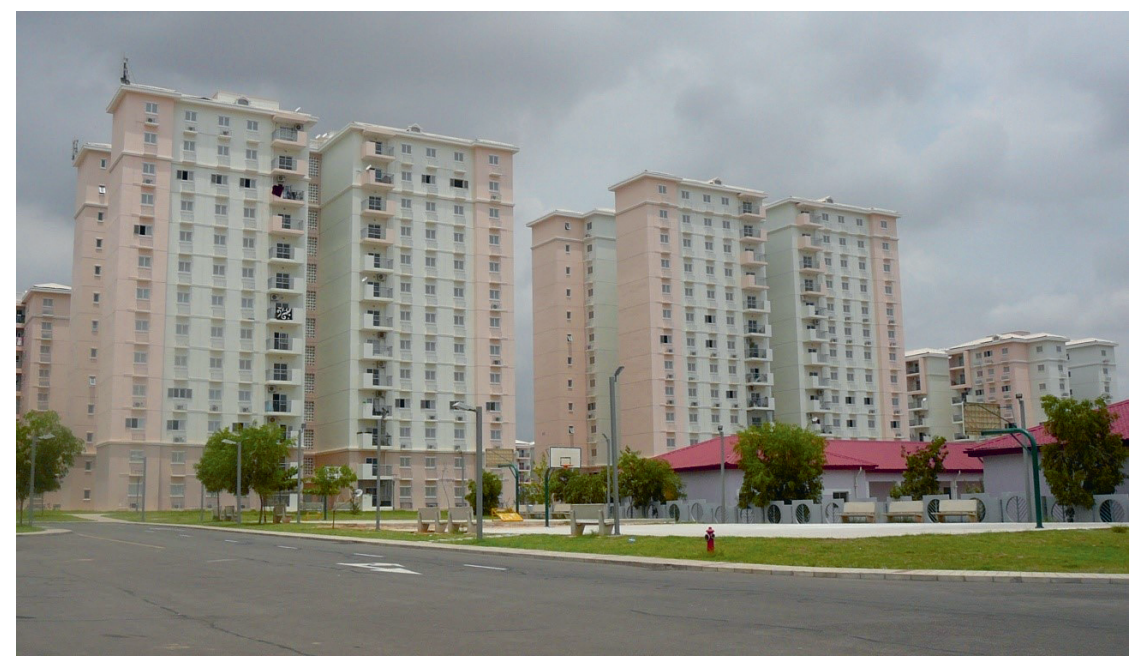

Figura 8.2 - Kilamba, Luanda, Angola, 2014. Fonte: Ilka B. Leite. 